\title{
Cytological Analysis of Body Fluids and Comparison of Precision in Diagnosis Between Conventional Smear and Cell Block Along with Clinical Correlation
}

\author{
Sridhar Honnappa, Ganraj Bhat S* and Prasanna Shetty B \\ Department of Pathology, M S Ramaiah Medical College, Mysore, India
}

\begin{abstract}
Background: The cytological analysis of serous effusions helps in diagnostic, therapeutic and prognostic implications especially in malignant effusions. This study determines the comparison of precision in cytological analysis between conventional smear and cell block in body fluids with clinical correlation. The study was conducted in M S Ramaiah medical college over a period of 2 years (2016-2018) in the department of pathology on total of 100 fluid cytology samples.

Methods and Material: Conventional smears and cell block for the same fluid was performed and cytological analysis done.The cytological data was analyzed for significance in correlation between smear and cell block. The results were tabulated and analyzed using SPSS version 15.0
\end{abstract}

Results: Cell block was diagnostically superior in $53.11 \%$ of cases as compared to conventional smear which was $18.22 \%$.However conventional smear was diagnostically inadequate in $33.98 \%$ of cases.

Conclusions: Cell block preparations can be combined with conventional smears wherever possible to improve diagnostic accuracy.

\section{Keywords: Conventional smear, Cell Block, Malignant effusions, Cytology.}

\section{Introduction}

Diagnostic cytology is the interpretation of cells exfoliated from epithelial surface or removed from tissue. The cytological analysis of serous effusions helps in diagnostic, therapeutic and prognostic implications. ${ }^{[1]}$ It is difficult to accurately identify the cellularity in conventional smears due to bland morphology of the cells, cellular overlapping, variation in laboratory techniques and useful material left back in the centrifuge tube in conventional smear method. ${ }^{[2,3]}$

This study determines the comparison of precision in cytological analysis between conventional smear and cell block in body fluids. Cell block was found to be a more specific technique for confirming the diagnosis given in conventional smear. However both the techniques combined together gave highest sensitivity and specificity in detecting malignant cases. At times, lack of morphological details of the representative cells contributes to considerable difficulties in making diagnosis on conventional smears. ${ }^{[2,3]}$ An attempt was made to utilize cell block technique in addition to the routine centrifuge method to overcome this difficulty.

\section{Material and Methods}

The study was approved by the institutional ethical and research committee of Ramaiah medical college,
Bangalore. The study was conducted over a period of 2 years (2016-2018) in the department of pathology. A total of 100 fluid cytology samples obtained from patients of various departments were analyzed. The clinical information including age, sex, history, provisional diagnosis was noted.

$10 \mathrm{ml}$ of fresh serous pleural, peritoneal, pericardial and cerebrospinal fluid samples received were first submitted for naked eye examination for physical characteristics and then subjected to conventional smear and cell block techniques. Around $5 \mathrm{ml}$ of sample was taken in test tube and centrifuged at $2500 \mathrm{rpm}$ for 15 minutes.A minimum of 2 thin smears were prepared from the sediment. The smears were stained with Papanicolaou as well as haematoxylin and eosin stains.

The rest $5 \mathrm{ml}$ of the sample was fixed with $5 \mathrm{ml}$ of $10 \%$ alcoholic formalin (90\% Ethyl alcohol and 10\% formalin) for 24 hours. This cell button was processed by dehydration, clearing and embedding.

4 micron thickness cell block sections were prepared from the cell button and the smears were stained with Haematoxylin and eosin and Papanicolaou stains. All the samples were subjected to systematic examination and scored as per the scoring system by Thapar $\mathrm{M}$ et al. ${ }^{[4]}$ 
Morphologic criteria such as cellularity, architecture and smear background were described and categorized.

An impression of

1) Acute or chronic inflammation,

2) Reactive effusion

3) Suspicious for malignancy

4) Positive for malignancy

Was given after detailed cytological assessment. The cytological diagnosis was correlated with clinical diagnosis and other specific laboratory investigations.

The results were tabulated and analyzed using SPSS version 15.0.Chi square test was used to analyse the benign and malignant lesions by CS \& CB method.

\section{Results}

100 samples were screened using conventional smear $\&$ cell block techniques simultaneously. The age of the patients range from 4-70 years, with maximum number of patients were in the age group of $40-60$ years. The samples of male patients (67) outnumbered the female patient's samples. Clinically, most common symptoms were abdominal distension, loss of weight, fever.

In our study, amongst the Pleural fluid samples(36), 30 were acute/chronic inflammation and 6 were malignant. Among the Peritoneal fluid samples(52), 46 were acute/ chronic inflammation and 6 were malignant. All the pericardial samples (2) were inflammatory. Amongst
Cerebrospinal fluid samples(10), 8 were inflammatory and 2 were malignant.

Conventional smear showed high sensitivity in detecting malignant cell but was low in specificity in confirming the malignant nature of tumor cells. Cell Block was high on both sensitivity and specificity in detecting and confirming the malignant nature of the effusions. Cell block was diagnostically superior and adequate in detecting the nature of the malignant cells based on cell morphology, and adequate content of the cells from the effusion. (Table 4)

The yield of cells with details of architectural pattern information about cellular with nuclear features, were more accurate in cell block as against the conventional smear method. It has been observed that conventional smear show individually dispersed cells, clusters, papillary fragments and acinar formations \& signet ring cells or keratinised cells in malignant fluid effusions, but the appreciation of architectural pattern of the malignant cytology, such as, three dimensional clusters, cell balls, sheets, cellular as well as nuclear pleomorphism, nuclear hyperchromatism, irregularity of the nuclear contours, type of chromatin, prominence of nucleoli, atypical mitotic figures and features of differentiation such as intracellular secretions, signet ring cells \& evidence of keratinisation is much better in cell blocks(Photomicrographs1\&2).Chi square test was used to analyse the benign and malignant lesions by CS \& CB method In which the $\mathrm{p}$ value was found to be highly significant.

Table 1:Distribution of cases among individual samples.

\begin{tabular}{|c|c|c|}
\hline Types of fluid & Number & Percentage \\
\hline Peritoneal & 52 & $36 \%$ \\
\hline Pleural & 36 & $02 \%$ \\
\hline Pericardial & 02 & $10 \%$ \\
\hline Cerebrospinal & 10 & $100 \%$ \\
\hline Total & 100 & 100 \\
\hline
\end{tabular}

Table 2: Peritoneal fluid analysis ,C S- conventional smear C B- Cell Block.

\begin{tabular}{|c|c|c|c|}
\hline Clinical diagnosis & No of cases & Cytological Diagnosis & No of cases \\
\hline & & & CS CB \\
\hline Peritonitis & 08 & Acute Inflammation & 0808 \\
\hline Cirrhosis with ascites & 30 & Chronic Inflammation & 3030 \\
\hline Fatty Liver & 07 & Chronic inflammation & 0707 \\
\hline Malignancy & 07 & Reactive Effusion & 0101 \\
\hline & & Suspicious for malignancy & 0400 \\
\hline
\end{tabular}


Table 3: Pleural fluid analysis.

\begin{tabular}{|c|c|c|c|}
\hline Clinical Diagnosis & No of cases & Cytological Diagnosis & No of cases \\
\hline & & & CS CB \\
\hline Pneumonia & 12 & Acute inflammation & 1212 \\
\hline Tuberculosis & 16 & Chronic inflammation & 1618 \\
\hline Malignancy & 08 & Reactive- & 0102 \\
\hline & & Suspicious- & $05-$ \\
\hline & & Positive - & 0206 \\
\hline Total & $\mathbf{3 6}$ & $\mathbf{3 6}$ & $\mathbf{3 6}$ \\
\hline
\end{tabular}

Table 4: Diagnostic scores of CS and CB.

\begin{tabular}{|l|c|c|}
\hline & CS & CB \\
\hline Diagnostically superior (6-9) & $18.22 \%$ & $53.11 \%$ \\
\hline Diagnostically adequate (3-5) & $47.80 \%$ & $42.80 \%$ \\
\hline Diagnostically unsuitable(0-2) & $33.98 \%$ & $4.09 \%$ \\
\hline
\end{tabular}

Table 5: Malignant effusions diagnosed by cell block method in pleural fluids.

\begin{tabular}{|c|c|c|c|}
\hline Malignant Effusions in pleural fluid Percentage & \multicolumn{2}{|c|}{ No of cases } & Total cases \\
\hline & Male & Female & 04 \\
\hline Lung 66.66 & 03 & 01 & 02 \\
\hline Breast 33.33 & - & 02 & $\mathbf{0 6}$ \\
\hline Total cases 100 & $\mathbf{0 3}$ & $\mathbf{0 3}$ & \\
\hline
\end{tabular}

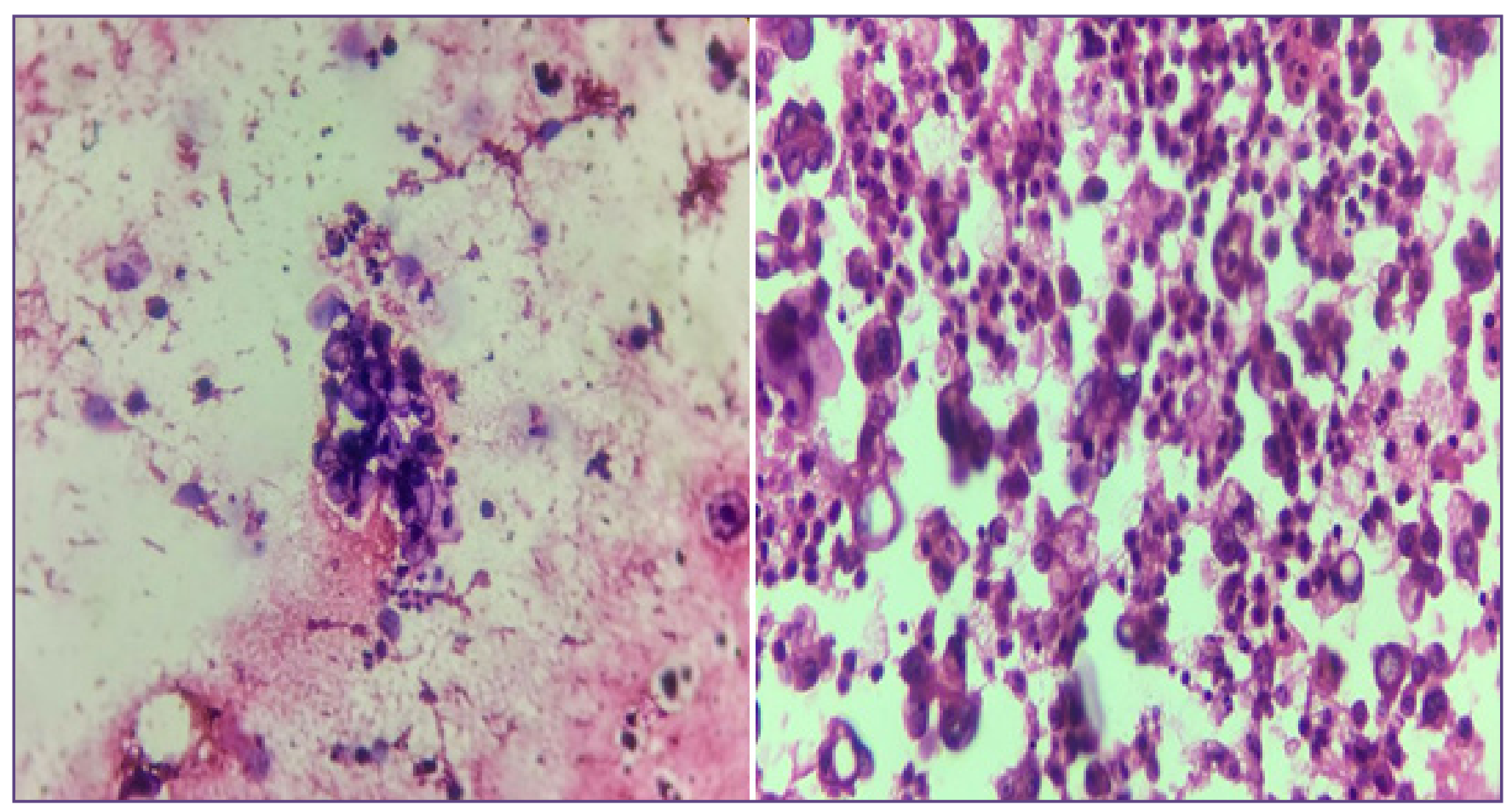

Fig. 1: Pleural fluid malignant effusion. (A) A smear showing few atypical cells arranged in clusters and singly. (X400, H\&E stain) (B)Cell block sections showing better cellularity and clear morphology of the atypical cells and clear background. (x400,H \&E stain). 


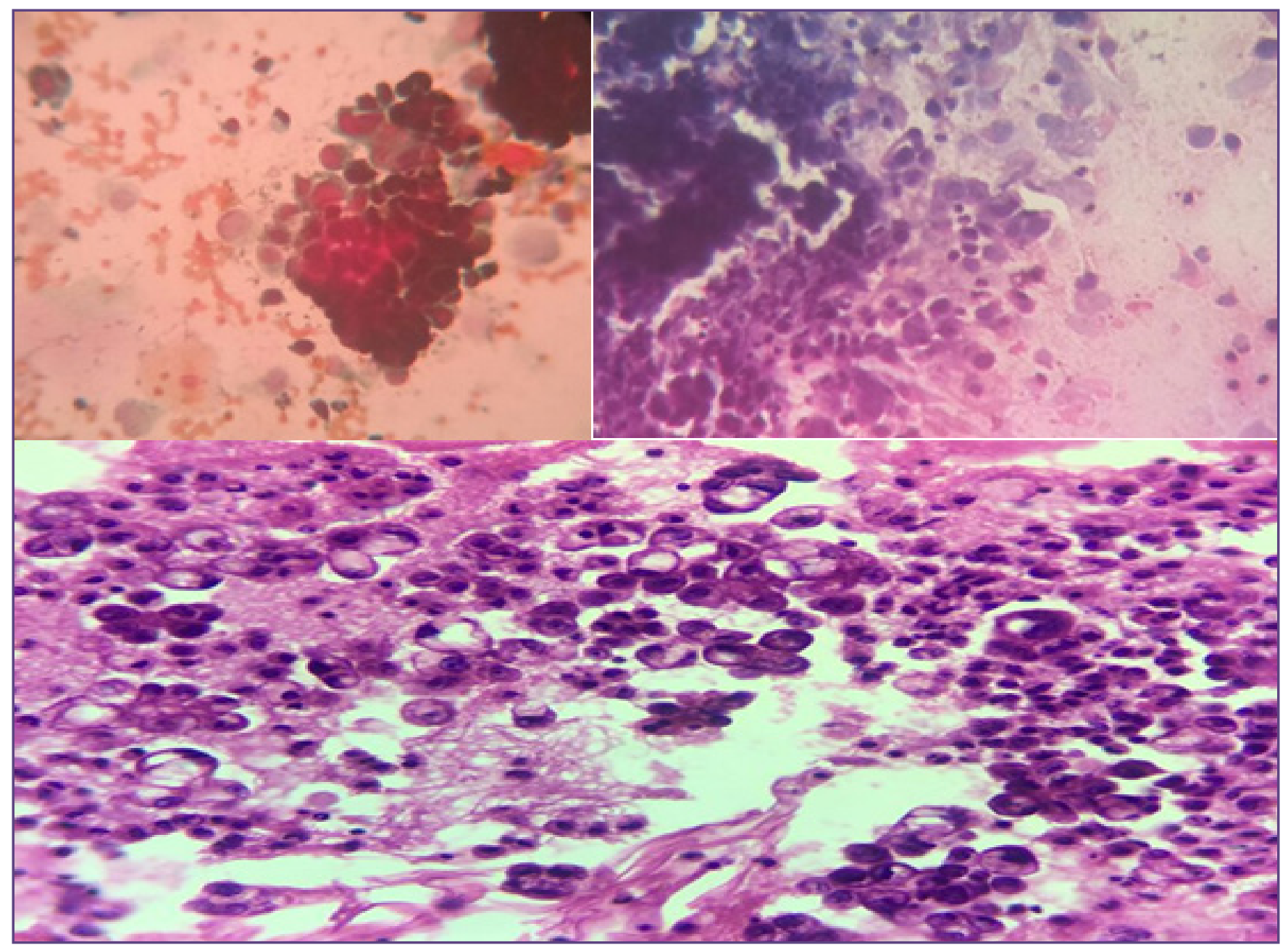

Fig. 2: Peritoneal fluid in malignant effusion.(A)(B) Smear showing clumps of atypical cells arranged in tight clusters with poor cell morphology. (x400,Papanicolaou,H\&E stain)(C) Cell block section showing clear morphology of the atypical cells with clear background and good cell quantity. (x400,H\&E stain).

\section{Discussion}

The cytological diagnosis of serous effusions is of paramount importance in diagnostic, therapeutic and prognostic aspects. Morphological details of cells are sometimes lacking in conventional smear which leads to difficult diagnosis. ${ }^{[2,3]}$ In the conventional smear method, there are plenty of reactive mesothelial cells, inflammatory cells, paucity of representative cells with lack of tissue architecture contribute to considerable difficulties which are faced while making the diagnosis. Reactive mesothelial cells show multinucleation, high nucleo cytoplasmic ratio which are great mimickers of malignant cell. It can be seen in chronic inflammation, infarction, post radiotherapy and chemotherapy. Conventional smear has the sensitivity of $40-70 \%$ for detecting the presence of malignant diseases due to the overcrowding of cells and processing artifacts.
The cell block method is used for processing all residual material after completion of cytological preparation. The material often contains valuable diagnostic evidence and tissue fragments that cannot be processed by cytological techniques. Malignant cells not present in the conventional smears often are found within the cell block. ${ }^{[4]}$

Cellblock technique was done to avoid difficult diagnosis in centrifuged samples. $10 \%$ alcohol-formalin as a fixative for cellblock preparation. Similar fixative was used in a study done by Bodele et al and in similar studies ${ }^{[5,6]}$ In a study conducted by Aruna et al, ${ }^{[7]}$ among 140 body fluid samples, 12 cases were reported as positive for malignant cells in which they were clinically not diagnosed. Increased diagnostic utility of $10 \%$ is noted in cell block method, as compared to $11 \%$ in our study. The preservation of morphological features in formalin cell block was better and comparable with studies by Khan et al. ${ }^{[8]}$ 
The cell block concentrated the cellular material into a small area which was useful in screening the material in lesser time. Thus cell block method increased detection of malignancy in body cavity effusion when used as an adjunct to conventional smears. Morphological features are better identified in cell block method thus improving sensitivity. Multiple sections can be taken from the same material for special stain, IHC thus improving specificity. ${ }^{[9]}$

In our study, out of 100 samples, 52 samples were peritoneal fluid, 36 were pleural, 10 were CSF and 2 were pericardial. In analysis of 52 peritoneal fluid samples 30 cases were cirrhosis liver and 6 were alcoholic liver disease.

Sujathan et al ${ }^{[10]}$ and Khan et al ${ }^{[8]}$ also observed the majority of cases in peritoneal fluid analysis the commonest being cirrhosis of liver with ascites. In pleural fluid analysis out of 36 samples, 18 cases were diagnosed as tuberculosis followed by pneumonia (12 cases) where the clinical cytological correlation was good in conventional and cellblock method which is similar to a study by Green LK et al ${ }^{[11]}$ and Humera Q.F et al ${ }^{[12]}$. Cellularity was more in cellblock sections compared to conventional smears.

Cellblock sections identified better architectural patterns such as sheets, acini, cell balls and papillary formation whereas conventional smears showed only singly scattered cells and small clusters. Cellblock sections were diagnostically superior as compared to conventional smears. These findings were consistent with the observations in the study done by Udasimath $\mathrm{S}$ et al. ${ }^{[13]}$

In the study by Matreja et $\mathrm{al}^{[14]}$ diagnostic yield of malignancy was $6.53 \%$ on conventional smear examination which was increased to $8.5 \%$ by cell block method. Similarly in a study by Bansode et.al, ${ }^{[14]} 15 \%$ yield for malignancy on conventional smear was increased to $18 \%$ on cell block study.

The additional yield of malignancy was found to be $11 \%$ more by cell block method compared to that attained by conventional smear in the present study. Majority of the cases with effusion showed reactive changes with the rest showing malignant effusion. Majority of the effusions were peritoneal and pleura fluids of which $31 \%$ of the cases showed malignant cytology (Table 2\&3).Lung carcinoma was the common cause for malignant pleural effusion and ovarian carcinoma was the most common cause in peritoneal fluids which were taken in the study respectively (Table 5). Similar to our study, Nair and Manjula et al have reported most common primary neoplasm causing pleural effusion as Carcinoma of the lung, followed by Carcinoma of the breast. ${ }^{[14]}$
In our study, additional yield of malignancy was found to be $11 \%$ more by cell block technique compared to that obtained by conventional smear which is similar to a study by Richardson et al ${ }^{[15]}$ which reduced the false negative results.

Statistical analysis of malignant body fluids revealed significant difference of $p$ value $<0.05$ in cellularity and diagnostic utility between conventional smear and cell block techniques.

\section{Conclusion}

We conclude that the cellblock technique is simple, inexpensive and does not require any special training or instrument. Cell block study has increased the diagnostic yield because of better preservation. It shows good architectural pattern, particularly in cases where there is a diagnostic dilemma between the malignancy and reactive changes. Conventional smear study is routinely practised since it is easier to perform and helps in diagnosis in short period of time.

The overall diagnostic accuracy of conventional smear and cell block sections in body fluid analysis was $94 \%$. Cell block preparations can be combined with conventional smears wherever possible to improve diagnostic accuracy.

\section{References}

1. Koss LG, Melamed MR, (Ed). Koss Diagnostic cytology and its histopathologic bases,5th edition, JB Lippincott Company: Philadelphia.2006; 922-1016.

2. Grunze H. The comparative diagnostic accuracy, efficiency and specificity of cytological techniques used in the diagnosis of malignant neoplasms in serous effusions of pleural and pericardial cavities.Acta Cytol1964; 8(2):150-63.

3. Fetsch PA, Simsir A, Brosky K, Abati A. Comparison of three commonly usecytologic preparations in effusions. Diagn Cytopathol.2002; 26(1):61-66.

4. Bhanvadia Viral M, Santwani P M, Vachhani JH. Analysis of diagnostic value of cytological smear method versus cell block method in body fluid cytology: study of 150 cases. Ethiop J Health Sci.2014;24(2):125-31.

5. Thapar M, Mishra RK, Sharma A, Goyal V. Critical analysis of cell block versus smear examination in effusions. J Cytol 2009; 26:60-4.

6. Nathan NA, Narayan E, Smith MM, Horn MJ. Cytologyimproved preparation and its efficacy in diagnostic cytology. Am J ClinPathol.2000; 114(4):599-606.

7. Mair, Dunbar F, Becker PJ, Du Plessis W. Fine Needle cytology: Is aspiration suctionnecessary. A study of 100 masses in various sites. Acta Cytol.1989; 33(6): 42-44.

8. Padmavati A, Sai Prasad BV, Anuradha B. A comparative study of fluid cytology with smear and cell block preparation. Journal of Evidence Based Medicine and Healthcare.2016;(3)65: 3532-3535. 
9. Khan N, Sherwani RK, Afroz N, Kapoor S. The cytodiagnosis of malignant effusions and determination of the primary site. J cytol, 2005; 22(3): 107-110.

10. Dey S, Nag D, Nandi A, Bandyopadhyay R. Utility of cell block to detect malignancy in fluid cytology: Adjunct or necessity? . Journal of Cancer Research and Therapeutics,2017;13(3):425-28.

11. Sujathan K, Kannan S, Mathew A, Pillai KR, Chandralekha B, Nair MK. Cytodiagnosis of serous effusions: A combined approach of morphological features in Papanicolaou and MGG stained smears and a modified cell block technique. Journal of Cytology.2000; 17(2):89-95.

12. Green LK., Griffin J. Increased Natural killer cells in fluids. Actacytol1996; 40(6): 1240-1245.
13. Humera QF, Ansari S, Maimoona M. Efficacy of Polymerase chain reaction overZiehl-Neelsen staining in the diagnosis of Mycobacterium tuberculosis. Int J Pharm BioSci,2012; 2(4):B 272-278.

14. Udasimath S, Arakeri SU, Karigowdar MH. Diagnostic utility of the cell block methodversus the conventional smear study in pleural fluid cytology. J Cytol.2012; 29(1):1115.

15. Matreja SS, Malukani K, Nandedkar SS, Varma AV, Saxena A, Ajmera A. Comparison of efficacy of cell block versus conventional smear study in exudative fluids. Nigerian Postgraduate journal.2018;24(4):245-49.

16. Richardson HL, Koss LG, Simon TR. Evaluation of concomitant use of cytological and histological technique in recognition of cancer in exfoliated material from various sources. Cancer.1955; 8:948-950.

*Corresponding author:

Dr Ganraj Bhat S, \#169, 3rd Main, 8th Cross, 2nd Stage, Bogadi (North), Mysore-26, INDIA

Phone: +91 9945527451

Email: gansi.bhat@gmail.com

Financial or other Competing Interests: None. 